\title{
¿La Alianza del Pacífico facilita la inserción de Colombia en la región Asia-Pacífico?*
}

\section{Does the Pacific Alliance make the insertion of Colombia in the Asia-Pacific region easier?}

\author{
Eric Tremolada Álvarez ${ }^{* *}$
}

Recibido: 30/05/2014

Aprobado: 06/06/2014

Disponible en línea: 01/07/2014

\section{Resumen}

Perú, Chile, México y Colombia están configurando una organización interestatal denominada Alianza del Pacífico, que se presenta como un nuevo esfuerzo de integración regional, que además de estimular intercambios comerciales y sinergias entre sus socios, sería una herramienta idónea para la inserción de Colombia en la región Asia-Pacífico, de ahí que el escrito aborde por un lado, el estudio de Asia-Pacífico como región, los acuerdos que están negociando los países que la configuran y el relacionamiento de estos con los países latinoamericanos. Por otra parte, analiza qué estamento de integración económica está configurando la Alianza del Pacífico y si su institucionalidad es consecuente con los propósitos que persigue.

\section{Abstract}

Peru, Chile, Mexico and Colombia are configuring an interstate organisation named Pacific Alliance, which is presented as a new regional integration effort, further stimulating the trade and synergies between partners that would be an ideal tool for the insertion of Colombia in the Asia-Pacific region. Hence the document deals with on one hand, the study of Asia-Pacific as a region, the agreements which are being negotiated and the relationship of these countries with Latin American countries. Moreover, it analyzes which body of economic integration is being configured with the Pacific Alliance and if its institutionality is consistent with the purposes pursued.

doi: 10.11144/Javeriana.PAPO19-2.apfi

${ }^{*}$ Artículo de Reflexión

** Abogado dedicado a la docencia e investigación del derecho internacional público y al derecho de la integración, titular en Colombia de la Cátedra Jean Monnet de Derecho de la Integración Comparado: Unión Europea - América Latina que se imparte en Universidad Externado con el aval de la Comisión Europea. Doctor en derecho de la Universidad de Valencia, tras haber obtenido un DEA en derecho internacional y relaciones internacionales por la Universidad Complutense de Madrid e Instituto Universitario Ortega y Gasset. Correo electrónico: eric.tremolada@uexternado.edu.co 


\section{Palabras clave:}

Región Asia-Pacífico; Alianza del Pacífico; libre circulación de bienes; servicios; capitales y personas; organizaciones internacionales; personalidad jurídica internacional

\section{Cómo citar este artículo:}

Tremolada, E. (2014). ¿La Alianza del Pacífico facilita la inserción de Colombia en la región Asia-Pacífico? Papel Político, 19(2), 721-752. http://dx.doi.org/10.11144/Javeriana.PAPO19-2.apfi

\section{Keywords:}

Asia-Pacific; Pacific Alliance; free circulation of goods, services, capital, and people; international organizations, international legal personality 
Los bloques económicos fomentan la especialización y esta a su vez, genera mayor productividad y eficiencia en los sectores donde se poseen ventajas comparativas que se traducirán en costos de producción más bajos La ampliación de mercados favorece la economía de escala internacional. Dentro de estas lógicas y de la mano de sus socios-competidores, Colombia entiende que mejoran sus posibilidades de inserción en Asia-Pacífico. De ahí que para saber si la Alianza del Pacífico es una herramienta idónea para la inserción de Colombia en la región Asia-Pacífico, necesitamos precisar en primer lugar, la configuración de esta región e investigar sobre los acuerdos de carácter económico que se están negociando en la misma.

Luego estudiaremos las relaciones económicas de América Latina con Asia-Pacífico haciendo énfasis en los indicadores que evidencian la participación de los países latinoamericanos en ese mercado y el número de acuerdos comerciales y de inversión sobre los que se soporta esta relación. Por su parte, teniendo en cuenta que los límites mínimos o máximos de la integración no están definidos, creando vínculos tenues o hasta lo más complejo, que sería la integración política (Dromi et al., 1995), pretenderemos establecer qué es la Alianza del Pacífico, con el propósito de saber qué clase de estamento de integración económica está constituyendo y así poder evidenciar si este corresponde a los propósitos de integración profunda anunciados ${ }^{1}$. A su vez, repasaremos los desarrollos de la Alianza para ver si estos son consecuentes con sus objetivos y si su estructura organizativa tiene una lógica institucional adecuada para soportarlos.

Por último, es necesario discutir si estamos frente a una organización internacional con personalidad jurídica que facilite negociaciones del bloque con terceros.

Así, fundamentados en un reciente estudio que se gestó en Bangkok, Tailandia, en el marco de una serie de ciclos académicos realizados entre el 11 y 16 de diciembre de 2013, desarrollaremos el planteamiento enunciado (Tremolada, 2014).

\section{Asia-Pacífico: ¿uuna región?}

Abunda la literatura que se refiere a Asia-Pacífico sin embargo, lo más difícil de establecer es ¿̇qué se entiende por Asia-Pacífico? Para unos es la cuenca o marco geográfico del océano Pacífico, explicación que se soportaría además, con la conformación del denominado Foro de Cooperación Asia-Pacifico APEC (Asia Pacific Economic Cooperation) donde tienen cabida países de Asia, Oceanía y América y que hoy cuenta con 21 Estados

\footnotetext{
${ }^{1}$ El profesor Lawrence precisa que en las integraciones superficiales se exige relativamente poco a las políticas nacionales, por el contrario, en una de carácter profundo toda distinción entre política nacional y comercial desaparece, al punto que cualquier uso discrecional de una regulación nacional puede interpretarse como un impedimento al comercio internacional. Las reglas internacionales acaban siendo en efecto, reglas nacionales (Rodrik, 2012).
} 
miembros de los tres continentes que rodean este océano². Sin embargo, el antecedente que empezó a perfilar la cuenca del pacífico como región data de 1967, momento en el que surge el Consejo Económico de la Cuenca del Pacífico PBEC (Pacific Basin Economic Council) que como organización informal, con participación de corporaciones empresariales, buscaba la facilitación de los negocios en la región. Inicialmente conformado por líderes de negocios de Estados Unidos, Canadá, Australia, Nueva Zelandia y Japón a los que se suman los de Corea del Sur, México, Hong Kong, Malasia y Filipinas ${ }^{3}$.

En 1980, para deliberar propuestas del PBEC, surgió el Foro de Cooperación Económica del Pacífico PECC (The Pacific Economic Cooperation Council), organización tripartita compuesta por empresarios, funcionarios de gobiernos y académicos, que como foro regional debaten - a título personal- sobre la cooperación y la coordinación de políticas que promueven el desarrollo económico en la región. Inicialmente contó con la representación de once economías, que hoy suman veintitrés, entre ellas la de Mongolia que no tiene salida al océano ${ }^{4}$.

Por su parte, para el Centro de Asia y el Pacífico, para Estudios de Seguridad APCSS (Asia Pacific Center for Security Studies) de los Estados Unidos, la región es más amplia e incluye países de Asia, aunque no toquen el Pacífico, así como la mayoría del cinturón de Oceanía y América que tocan el Pacífico: 49 Estados en total ${ }^{5}$. Como dice Francisco Barbosa, la génesis de los organismos y mecanismos de integración en la región, evidencia que "Washington no solamente ha estado atento a sus desarrollos sino que ha participado activamente en ellos, frenándolos o impulsándolos, promoviéndolos o sumándose a los mismos”. De ahí que la integración asiática hacia adentro, con base en el fortalecimiento de la identidad regional, no sea una realidad y abra paso al diálogo transpacífico (Barbosa, Posada y Serrano, 2011, p. 62).

Así, con el único propósito de configurar a Asia-Pacífico como una región definida en la que Colombia pretende insertarse, trataremos de enmarcarla -con base en la división

\footnotetext{
${ }^{2}$ Foro de Cooperación Económica de Asia-Pacífico, APEC (Asia Pacific Economic Cooperation), integrado por Australia, Brunei, Canadá, Chile, China, Estados Unidos de América, Hong Kong, Indonesia, Japón, República de Corea, Filipinas, Malasia, México, Nueva Zelandia, Papua Nueva Guinea, Perú, Rusia, Singapur, Tailandia, Taiwán y Vietnan. En http://www.apec.org/

${ }^{3}$ Consejo Económico de la Cuenca del Pacífico, PBEC (Pacific Basin Economic Council) http:// www.pbec.org/

${ }^{4}$ El Foro de Cooperación Económica del Pacífico, PECC (The Pacific Economic Cooperation Council) lo componen veintitrés comités de Australia, Brunei Darussalam, Canadá, Chile, China, Colombia, Ecuador, Hong Kong, Indonesia, Japón, Corea, Malasia, México, Mongolia, Nueva Zelandia, Perú, Filipinas, Singapur, Tailandia, Taiwan, Estados Unidos, Vietnam y el Foro de las Islas del Pacífico. En https://www.pecc.org

${ }^{5}$ Centro de Asia y el Pacífico para Estudios de Seguridad, APCSS (The Asia-Pacific Center for Security Studies), en http://www.apcss.org/about-2/ap-countries/
} 
de la ONU- como el conjunto de países que conforman, por el lado asiático, Asia Oriental (China, Corea del Norte, Corea del Sur, Japón, Mongolia y Taiwán) y el Sudeste Asiático (Birmania, Brunéi, Camboya, Filipinas, Indonesia, Laos, Malasia, Singapur, Tailandia, Timor Oriental y Vietnam). Por el lado de Oceanía, Australia, Nueva Zelandia y las islas de Nueva Guinea descartando Melanesia, Micronesia y Polinesia ${ }^{6}$.

\section{El inmenso bloque económico que se está configurando en Asia-Pacífico}

En 2011, en el marco de la Cumbre de la ASEAN, China y Japón conjuntamente plantearon la necesidad de negociar un acuerdo regional de integración que más tarde se denominaría Acuerdo de Asociación Económica Integral Regional, RCEP (Regional Comprehensive Economic Partnership)7. No obstante, el consenso para el inicio de las negociaciones que incluirían los diez miembros de la ASEAN y seis socios, solo se dio a finales de 2012, durante la $44^{\text {a }}$ Reunión de Ministros de Economía de la ASEAN ${ }^{8}$.

La crisis económica mundial y las presiones de Estados Unidos para consolidar una Asociación Trans-Pacífico (TPP) con exigentes requerimientos de propiedad intelectual y protección de las inversiones, hicieron que China cambiara sus prioridades en la región aproximándose a ella e impulsando un acuerdo regional, que necesariamente revaluaría su rivalidad permanente con Japón. La propuesta conjunta de chinos y japoneses acelera la constitución del Área de Libre Comercio de Asia Oriental, EAFTA (East Asia Free Trade Area) ${ }^{10}$-que incluye a los diez miembros de la ASEAN más China, Japón y Corea (ASEAN más tres) - y con la que se siente más cómoda China y la Asociación Económica en Asia Oriental, CEPEA (Comprehensive Economic Partnership in East Asia), que se basa en ASEAN más China, Japón, Corea, India ${ }^{11}$, Australia y Nueva Zelandia (ASEAN 6) y que privilegia Japón ${ }^{12}$.

Las negociaciones de EAFTA y CEPEA han tenido desarrollos paralelos, por un lado EAFTA negoció una zona de libre comercio, mientras que CEPEA se centró en el

\footnotetext{
${ }^{6}$ Así, de manera arbitraria, teniendo en cuenta la inserción que busca Colombia, excluimos a Rusia y los países de América.

7 Nineteenth ASEAN Summit, Bali, Indonesia, 14-19 November 2011.

${ }^{8}$ La Asociación de Naciones del Sudeste Asiático, ASEAN (Association of Southeast Asian Nations), organización regional de Estados gestada el 8 de agosto de 1967 por Tailandia, Indonesia, Malasia, Singapur y Filipinas a la que se suman Vietnam, Laos, Camboya, Brunéi y Birmania. Estos diez miembros, junto con Japón, Corea del Sur y China, forman el foro denominado "ASEAN más Tres". Con India, Australia y Nueva Zelanda se completan los dieciséis Estados que están negociando el RCEP. ${ }^{9}$ East Asia Forum. Economics, Politics and Public Policy in East Asia and the Pacific. Consultado el 01.02.2014. En http://www.eastasiaforum.org/2011/12/11/east-asian-free-trade-area-bank-on-it/ ${ }^{10}$ La idea EAFTA fue lanzada en noviembre de 2001 por East Asia Vision Group.

${ }^{11}$ India, de acuerdo con la división por regiones de la ONU en Asia, pertenece a Asia Meridional.

12 Japón propuso CEPEA en 2006.
} 
desarrollo institucional y la cooperación económica. Estos dos entendimientos complementarios son los que fundamentan la RCEP e incluye a todos los miembros de ASEAN 6. El Acuerdo de Asociación Económica Integral Regional, RCEP, pretende alcanzar un acuerdo integral y beneficioso para todos sus miembros, lo que implica un compromiso más profundo y a diferencia de las acostumbradas membresías predeterminadas, RCEP se consolida en una adhesión abierta y flexible que permite a los dieciséis a participar desde el comienzo de las negociaciones o cuando estos se sientan listos, sin perjuicio de que se vinculen socios económicos externos ${ }^{13}$.

Esto permite una consideración más generosa de las necesidades de cada Estado, maximizando los beneficios y reduciendo los costos para las empresas. Compatible con las normas vigentes de la $\mathrm{OMC}$, debe centrarse en reformas estructurales internas que son necesarias para la aplicación de medidas de liberalización. Negocia un enfoque simplificado y armonizado de las normas de origen que permite la acumulación y reduce los costos de transacción y de tiempo. En materia del comercio de servicios y barreras no arancelarias, tiene que superar muchas sensibilidades. En todo caso, el sector turismo y el desarrollo de estándares regionales, que simplifiquen y armonicen las licencias y los procedimientos aduaneros y desarrollen enfoques comunes a los métodos de prueba y evaluaciones de conformidad, se constituyen en una posibilidad real para superarlas ${ }^{14}$. En el capítulo de inversión las negociaciones abarcan los cuatro pilares tradicionales, esto es: promoción, protección, facilitación y liberalización.

Para abordar el universo de cuestiones se establecieron cuatro grupos de trabajo: 1) propiedad intelectual, 2) competencia, 3) cooperación económica y técnica y 4) solución de diferencias. Esto ha facilitado el avance de las negociaciones al punto que la cuarta ronda se dará en China en el próximo mes de abril. Si a finales de 2015 -meta que se impusieron los 16 Estados negociadores- se suscribe el acuerdo, estaremos frente a un bloque comercial que incluirá más de 3 mil millones de personas ${ }^{15}$, tendrá un PIB combinado de alrededor de $\$ 17$ billones de dólares ${ }^{16}$ y representará alrededor del 40 por ciento del comercio mundial ${ }^{17}$.

\footnotetext{
${ }^{13}$ East Asia Forum. Economics, Politics and Public Policy in East Asia and the Pacific. Consultado en http://www.eastasiaforum.org/2012/08/27/asias-regional-comprehensive-economic-partnership/ ${ }^{14}$ East Asia Forum. Economics, Politics and Public Policy in East Asia and the Pacific. Consultado en http://www.eastasiaforum.org/2012/08/27/asias-regional-comprehensive-economic-partnership/ ${ }^{15}$ Se trata de $46 \%$ de la población mundial de conformidad con World Economic Outlook Databases (octubre 2013) del Fondo Monetario Internacional.

${ }^{16}$ Esto es aproximadamente 24\% del PIB mundial de conformidad con World Economic Outlook Databases (octubre 2013) del Fondo Monetario Internacional.

${ }^{17}$ Regional Comprehensive Economic Partnership (RCEP): Issues and Way Forward. The Diplomat, July 30, 2013. En http://thediplomat.com/2013/07/regional-comprehensive-economic-partnership -rcep-issues-and-way-forward/
} 


\section{Las relaciones de América Latina con Asia Pacífico}

El Boletín Estadístico No 3 del 2013 del Observatorio América Latina-Asia Pacífico, destaca que la región Asia-Pacífico ${ }^{18}$ se viene convirtiendo en un socio comercial de trascendencia para América Latina y el Caribe. En el primer semestre de 2013, 19\% de nuestras exportaciones se dirigieron a esta región y 27\% de nuestras importaciones se originaron allá. Cabe señalar que China es el principal socio individual y como tal sus participaciones fueron de $9 \%$ y $13 \%$ respectivamente.

Entre enero y junio de 2013 el monto de las exportaciones de bienes de nuestra región a Asia-Pacífico alcanzó los 102.000 millones de dólares registrando un aumento de 5,1\% en relación con el mismo período de 2012. En el mismo lapso, las importaciones regionales de bienes desde Asia-Pacífico alcanzaron los 142.000 millones de dólares, presentando un déficit comercial de 40.000 millones de dólares.

En este período, el mejor desempeño también se evidenció en la diversidad de destinos, especialmente a la India, la República de Corea y las economías de la ASEAN. En el caso de nuestras importaciones, el mayor dinamismo se registra en las compras desde la República de Corea, China y la ASEAN, mientras que las importaciones desde Japón mostraron un descenso.

Perú y Chile, dos de los principales exportadores regionales a Asia Pacífico, mostraron descensos de sus exportaciones en este período de $12 \%$ y 4,9\% respectivamente. Guatemala y Honduras registraron los mayores descensos de los valores exportados a Asia Pacífico en el primer semestre de 2013, aunque esta disminución no tiene mayor incidencia en el total exportado por la región. Contrariamente, el resto de los países mostró un crecimiento en el valor de sus envíos, destacándose los casos del Uruguay (+70\%), Paraguay $(+56 \%)$ y Colombia (+46\%). Brasil, Chile, Venezuela, México, Argentina y Perú son los principales orígenes de las exportaciones. Se destaca el caso de Brasil que representó el 37\% de las exportaciones regionales a Asia-Pacífico y 46\% de las dirigidas a China.

En particular la relación deficitaria con Asia-Pacífico, se destacan el caso de México, que supera al conjunto de los déficits que registra el resto de los países (48.00o millones de dólares) y los casos excepcionales de superávits de Brasil, Chile y Venezuela.

En este período los precios de los productos básicos que exportamos cayeron 1,5\%, con bajas del cobre y sus derivados (-5\%) y del petróleo (-5\%), que se encuentran dentro de los principales productos de exportación a Asia-Pacífico. De la canasta exportadora, únicamente la soja $(0,7 \%)$ y el hierro $(0,5 \%)$ registraron leves aumentos de precios. En

\footnotetext{
${ }^{18}$ Para efectos del Boletín Estadístico № 3 del 2013 del Observatorio América Latina-Asia Pacífico, la agregación Asia-Pacífico incluye los flujos comerciales con Asia en su conjunto y Oceanía. En http://www.observatorioasiapacifico.org/
} 
volumen de exportaciones, se destaca la caída del hierro, cercana a 22\% y del cobre (-5\%). En el caso de la soja, se observó un incremento del volumen exportado (22\%).

Las exportaciones -aunque concentradas en productos básicos- siguen presentándose dinámicas pese a su desaceleración en los últimos dos años, habiéndose multiplicado por un factor de 3,5 desde 2006. Entre enero y junio de 2013, el promedio mensual exportado a Asia-Pacífico por la región fue de 17.000 millones de dólares, frente a 4.900 millones de dólares en 2006. Algo similar ocurre con las importaciones que se multiplicaron en 2,5.

La dinámica exportadora de Colombia con destino Asia-Pacífico, si bien no se ha multiplicado al ritmo de América Latina, desde el 2006 -de manera sostenida y creciente a partir de 2009- se ha duplicado, pasando de 3.53 a 6.06 millones de dólares en 2012, siendo deficitaria tan solo en 26.302 dólares. El 43.7\% de nuestras exportaciones se concentran en el rubro de combustibles minerales, aceites minerales y productos de su destilación, materias bituminosas y ceras, el 21.2\% en fundición, hierro y acero, el 14\% en café, té, yerba mate y especias y $4.5 \%$ en productos diversos de las industrias químicas ${ }^{19}$.

\section{Destino de exportaciones colombianas a la región Asia-Pacífico 2006-2013}
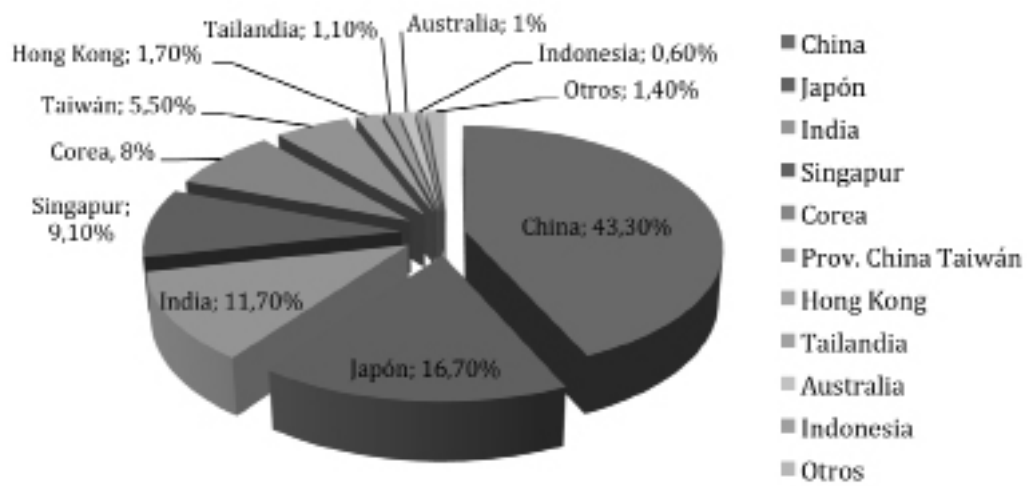

Fuente: Con base en datos de ALADI y COMTRADE (América Latina) y COMTRADE (Asia Pacífico)

Esta misma tendencia se evidencia, si se particulariza con la ASEAN en Colombia con destino a este bloque desde el 2006 -de manera sostenida y creciente a partir de 2009- que ha duplicado sus exportaciones, pasando de 770.00o dólares a 1,26 millones de dólares en 2012, presentando un sutil superávit de 33. ooo dólares. En este caso $71.7 \%$ de nuestras exportaciones se concentran en el rubro de combustibles minerales,

${ }^{19}$ Con base en datos de ALADI y COMTRADE (América Latina) y COMTRADE (Asia Pacífico). Consultada el 03.02.2104 a través del Monitor Económico-Comercial del Observatorio América Latina - Asia Pacífico. En http://www.observatorioasiapacifico.com/ 
aceites minerales y productos de su destilación, materias bituminosas y ceras, $6.5 \%$ en fundición, hierro y acero y 4.5\% en productos diversos de las industrias químicas ${ }^{20}$.

\section{Destino de exportaciones colombianas a la ASEAN 2006-2013}

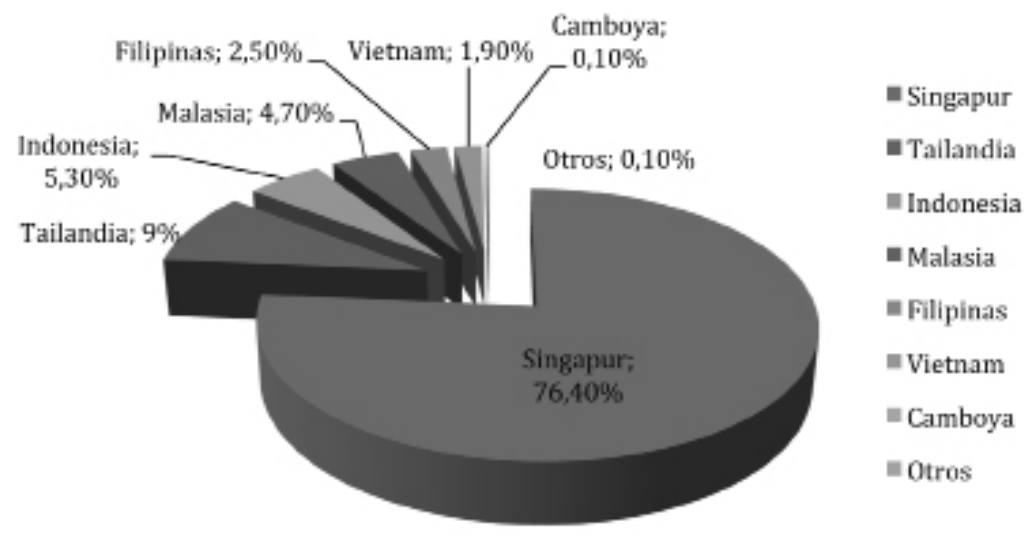

Fuente: Con base en datos de ALADI y COMTRADE (América Latina) y COMTRADE (Asia Pacífico)

Nuestra oferta exportadora, el interés de nuestros empresarios en Asia-Pacífico, las expectativas al alza y a la diversidad, en una región donde nuestros competidores ya cuentan con preferencias comerciales que pueden estar desplazándonos, las posibilidades de atraer inversiones con socios que salvaguarden los intereses de los inversionistas colombianos $^{21}$, la factibilidad política de negociar y celebrar acuerdos bilaterales o en bloque y la disposición al libre comercio, priorizaron esta región como un socio estratégico. Dentro de esta lógica, Colombia escoge sus socios comerciales (Vilar, 2013, p. 395).

\section{Presencia de los competidores latinoamericanos en Asia- Pacífico}

De los países latinoamericanos proveedores de bienes a Asia-Pacífico, Colombia ocupa el octavo lugar con 1,9\%, superado ampliamente por Brasil que representa 37,1\%, Chile 20,6\%, México 10,1\%, Argentina 8,4\%, Venezuela 7,7\%, Perú 6,3\% y Costa Rica 3,6\%; solo superamos a Panamá y Uruguay que tienen una participación de o,8\% cada uno. Si

${ }^{20}$ Con base en datos de ALADI y COMTRADE (América Latina) y COMTRADE (Asia Pacífico). Consultada el 03.02.2104 a través del Monitor Económico-Comercial del Observatorio América Latina - Asia Pacífico. En http://www.observatorioasiapacifico.com/

${ }^{21}$ La inversión extranjera directa (IED) de Asia-Pacífico en Colombia es realmente escasa, pasó de 209.000 dólares en 2006 a 408.000 dólares en 2012 y si tomamos en el mismo período y dentro de estos datos a la ASEAN, vemos que este bloque invirtió en Colombia 64.000 dólares en 2006 que pasaron a 112.000 dólares en 2012. La IED de Colombia en Asia-Pacífico es prácticamente nula, ascendió en 2012 a 16.000 dólares. Fuente datos de CEPAL (América Latina) y UNCTAD (Asia Pacífico). 
miramos la participación como proveedores solo de la ASEAN, Brasil representa 35,1\%, Argentina 18,5\%, Venezuela 12,5\%, México 11,2\%, Costa Rica 7,6\%, Chile 7,3\%, Perú $1,9 \%$, Colombia 1,8\% y Panamá y Uruguay $1,1 \%^{22}$.

Adicionalmente, nuestros socios y competidores regionales cuentan con preferencias pactadas que facilitan su inserción comercial en los países de la región Asia-Pacífico. Chile cuenta con tratados de libre comercio en vigor con Corea desde 2004 y con China desde 2006, año en que entró en vigencia la zona de libre comercio pactada con Brunéi, Nueva Zelanda y Singapur en el marco del denominado TPP, que además cuenta, desde 2007, con acuerdos, uno de alcance parcial con India y otro de la Asociación Económica Estratégica con Japón y que suscribió tres TLC más, uno con Malasia en vigor desde el 2012 y otros dos con Tailandia y Vietnam que están suscritos y perfeccionando su entrada en vigor.

Por su parte, México tiene vigente una Asociación Económica con Japón desde 2005y se encuentra en proceso de negociación de otros seis acuerdos de liberalización con Australia, Malasia, Vietnam, Brunei, Nueva Zelanda y Singapur, los tres últimos en el marco del TPP.

Perú tiene TLC vigentes con Singapur desde 2009, con China en 2010, con Corea y Tailandia desde 2011, uno de asociación económica con Japón desde 2012 y cinco acuerdos de liberalización en negociación con Australia, Brunei, Malasia, Nueva Zelanda y Vietnam. Argentina, Brasil, Paraguay y Uruguay en el marco del Mercosur, tienen un Acuerdo Preferencial de Comercio con la India vigente desde 2009. Costa Rica cuenta con tratados de libre comercio con China y Singapur vigentes desde 2011 y 2013 respectivamente y uno en estudio con Corea.

En contraste, Colombia no tiene en vigor ningún acuerdo preferencial en la región AsiaPacífico. En 2013 suscribió uno con Corea que está en proceso de ratificación, adelanta una negociación con Japón y tiene en estudio uno con $\mathrm{China}^{23}$. En materia de acuerdos sobre Promoción y Protección de Inversiones entre países latinoamericanos y de Asia-Pacífico el panorama para Colombia no es tan desalentador, si tenemos en cuenta el número de acuerdos en vigor, Argentina cuenta con diez, Chile con ocho, Perú con siete, México y Uruguay con cinco, Colombia con cuatro, Costa Rica y Cuba con tres, Guatemala, Nicaragua y Panamá con dos, y Ecuador, El Salvador, Honduras y Paraguay con un solo acuerdo ${ }^{24}$.

\footnotetext{
${ }^{22}$ Fuente: Con base en datos de ALADI y COMTRADE (América Latina) y COMTRADE (Asia Pacífico). ${ }^{23}$ ALADI, CAF y CEPAL, sobre la base de información de la Organización de Estados Americanos, Sistema de Información del Comercio Exterior (SICE) e información de los Ministerios de Comercio y Relaciones Exteriores de los países latinoamericanos. Cifras contrastadas a través del Monitor de acuerdos y negociaciones del Observatorio América Latina - Asia Pacífico. En http://www. observatorioasiapacifico.com/

${ }^{24}$ ALADI, CAF y CEPAL, sobre la base de información de la Organización de Estados Americanos, Sistema de Información del Comercio Exterior (SICE) e información de los Ministerios de Comercio y Relaciones Exteriores de los países latinoamericanos. Cifras contrastadas a través del Monitor
} 


\section{Acuerdos vigentes sobre Promoción y Protección de Inversiones entre países latinoamericanos y países de la región Asia-Pacífico}

\begin{tabular}{|c|c|c|c|c|c|c|c|c|c|c|c|c|c|c|c|c|c|c|}
\hline & 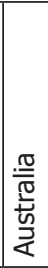 & 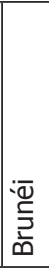 & 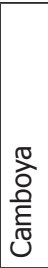 & 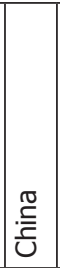 & 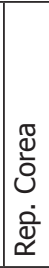 & 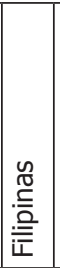 & 䓂 & 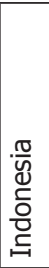 & 总 & $\begin{array}{l}n \\
0 \\
\Xi\end{array}$ & $\begin{array}{l}\frac{\cdot \pi}{\sqrt{2}} \\
\frac{\pi}{\pi} \\
\frac{\pi}{2}\end{array}$ & 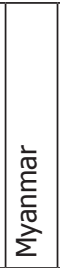 & 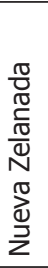 & 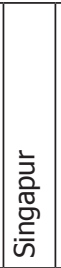 & 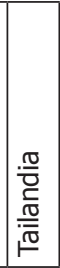 & 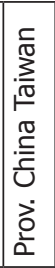 & 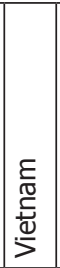 & 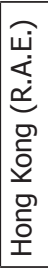 \\
\hline Argentina & & & & & & & & & & & & & & & & & & \\
\hline Bolivia & & & & & & & & & & & & & & & & & & \\
\hline Brasil & & & & & & & & & & & & & & & & & & \\
\hline Chile & & & & & & & & & & & & & & & & & & \\
\hline Colombia & & & & & & & & & & & & & & & & & & \\
\hline Costa Rica & & & & & & & & & & & & & & & & & & \\
\hline Cuba & & & & & & & & & & & & & & & & & & \\
\hline Ecuador & & & & & & & & & & & & & & & & & & \\
\hline El Salvado & & & & & & & & & & & & & & & & & & \\
\hline Guatemala & & & & & & & & & & & & & & & & & & \\
\hline Honduras & & & & & & & & & & & & & & & & & & \\
\hline México & & & & & & & & & & & & & & & & & & \\
\hline Nicaragua & & & & & & & & & & & & & & & & & & \\
\hline Panamá & & & & & & & & & & & & & & & & & & \\
\hline Paraguay & & & & & & & & & & & & & & & & & & \\
\hline Perú & & & & & & & & & & & & & & & & & & \\
\hline Rep. Domir & & & & & & & & & & & & & & & & & & \\
\hline Uruguay & & & & & & & & & & & & & & & & & & \\
\hline Venezuela & & & & & & & & & & & & & & & & & & \\
\hline
\end{tabular}

Fuente: ALADI, CAF y CEPAL, sobre la base de información de la Organización de Estados Americanos, Sistema de Información del Comercio Exterior (SICE) e información de los ministerios de Comercio y Relaciones Exteriores de los países latinoamericanos

Por su parte, durante todo el 2013 continuaron las negociaciones entre los doce países participantes del Acuerdo de Asociación Transpacífico, más conocido por sus siglas en inglés TPP (Trans Pacific Partnership). Durante los últimos tres años se han desarrollado formalmente diecinueve rondas de negociación que buscan concretar una alianza económica estratégica Trans-Pacífico. El origen de esta negociación se basa en el acuerdo Pacific Three Closer Economic Partnership (P3-CEP), que empezó negociaciones en la cumbre del Foro de Cooperación Económica Asia-Pacífico (APEC) 2002 con Chile, Nueva Zelanda y Singapur. Brunéi se sumó en 2005 y desde ese momento se conoció como Acuerdo P4, entró en vigor en noviembre de 2006.

de acuerdos y negociaciones del Observatorio América Latina - Asia Pacífico. En http://www. observatorioasiapacifico.com/ 
Estados Unidos empezó a negociar con los miembros del Acuerdo P4 en febrero de 2008. Ese mismo año, en el mes de noviembre, se sumaron a las negociaciones Australia, Perú y Vietnam, Malasia se incorporó en 2010, México y Canadá en 2012 y en marzo de 2013 Japón, en septiembre y noviembre del mismo año, Taiwán y Corea anunciaron formalmente su interés ${ }^{25}$.

Este acuerdo que está próximo a cerrarse, solo contando a los cuatro países originarios y los ocho que vienen negociando, configuraría un área de libre comercio de 790 millones de personas, que concentraría la tercera parte del comercio global y un PIB mundial cercano al 40\%. Nótese que los doce Estados que participan del TPP son partes de la $\mathrm{APEC}^{26}$ donde siete de ellos a su vez, son negociadores del $\mathrm{RCEP}^{27}$, cuatro miembros de la $\mathrm{ASEAN}^{28}$ y tres de la Alianza del Pacífico ${ }^{29}$.

\section{El área de integración regional Alianza del Pacífico}

Chile, Colombia, México y Perú, en busca de un instrumento esencial para el desarrollo económico y social sostenible, decididos a fortalecer los diferentes esquemas de integración en América Latina como espacios de concertación y convergencia, orientados a fomentar el regionalismo abierto, que los inserte eficientemente en el mundo globalizado y los vincule a otras iniciativas de regionalización, constituyeron un área de integración regional con el Tratado de Paranal (Antofagasta, Chile) ${ }^{30}$.

No obstante, el regionalismo abierto -que se resalta en el Preámbulo del Tratadopretende insertar a los Estados parte al mundo y vincularlos con otros acuerdos regionales de integración. Pero lo primero que conspira contra este propósito es el fundamento en que se soporta la Alianza, esto es "los acuerdos económicos, comerciales y de integración vigentes entre las partes a nivel bilateral, regional y multilateral" ${ }^{31}$, todos estos discriminan a terceros con fundamento en las normas de origen ${ }^{32}$, lo que desvirtuaría

\footnotetext{
${ }^{25}$ Organización de Estados Americanos, Sistema de Información del Comercio Exterior (SICE). En http://www.sice.oas.org/

${ }^{26}$ Nos estamos refiriendo al Foro de Cooperación Económica de Asia-Pacifico, APEC (Asia Pacific Economic Cooperation). Foro integrado por Australia, Brunei, Canadá, Chile, China, Estados Unidos de América, Hong Kong, Indonesia, Japón, República de Corea, Filipinas, Malasia, México, Nueva Zelanda, Papua Nueva Guinea, Perú, Rusia, Singapur, Tailandia, Taiwán y Vietnan. En http://www.apec.org/ ${ }^{27}$ Australia, Nueva Zelandia, Brunei, Malasia, Singapur, Vietnam y Japón.

${ }^{28}$ Brunéi, Malasia, Singapur y Vietnam.

${ }^{29}$ Chile, Perú y México.

${ }^{30}$ Preámbulo y artículo $1^{\circ}$ del Tratado de Paranal del 6 de junio de 2012, constitutivo de la Alianza del Pacífico.

${ }^{31}$ Preámbulo del Tratado de Paranal del 6 de junio de 2012, constitutivo de la Alianza del Pacífico. 32 Véanse los acuerdos de libre comercio de Chile con México (1998), Colombia y Perú (2006), México con Colombia (1995), Chile (1999) y Perú (2012) y entre Perú y Colombia (Comunidad Andina).
} 
la vinculación con otros acuerdos a menos que se negocie un acuerdo de integración entre bloques, que por supuesto también discriminaría a terceros ${ }^{33}$ (Tremolada, 2013 b).

Adicionalmente, la estrategia de chilenos, mexicanos, peruanos y colombianos de pertenecer a muchos acuerdos comerciales, si bien es atractiva al combinar el acceso libre a varios mercados con importaciones de diversas fuentes, como precisan Schiff y Winters (2003), puede ocasionar superposición de obligaciones ${ }^{34}$

En relación con sus objetivos, en el primero de estos se señala la necesidad de “construir, de manera participativa y consensuada, un área de integración profunda para avanzar progresivamente hacia la libre circulación de bienes, servicios, capitales y personas" (Schiff y Winters, 2003).

Pero ¿̇qué se entiende por integración profunda y cómo puede esta soportar la liberalización de los bienes, servicios, capitales y personas? Para contestar estos interrogantes, acudiendo al marco teórico de la integración económica ${ }^{35}$, debemos precisar que la integración como institución jurídica de carácter económico, donde los Estados miembros cooperan para ampliar sus intercambios comerciales, se basa en acuerdos que configuran espacios económicos (zonas) donde los países se conceden determinadas ventajas, según su voluntad política. Así, la configuración de la zona responderá a la etapa o estamento de integración económica pactado.

Si las partes de un tratado solo se otorgan ventajas recíprocas en materia de aranceles estaremos frente a unas "preferencias arancelarias”. Si lo que configuran es una zona donde de manera recíproca eliminarán o disminuirán significativamente sus aranceles y las barreras no arancelarias a su comercio, lo que se configura es una 'zona de libre comercio'. Si sobre la base de lo anterior se pacta además, el establecimiento de un arancel externo común para el comercio con terceros países o regiones se configura una 'unión tarifaria' también denominada 'unión de consumidores'.

Si a una unión tarifaria se le crea un organismo supranacional de aduanas que recibe y distribuye los ingresos fiscales percibidos por los productos de terceros países que entran a la zona, estaremos frente a una 'unión aduanera'. Unión tarifaria y unión aduanera no son conceptos análogos, tienen diferencias sustanciales, esto es que el arancel que pagan los bienes y/o servicios de los países ajenos a la zona se queda, en el caso de la

\footnotetext{
${ }^{33}$ El regionalismo tiende más a menoscabar el pleno comercio que a apoyarlo y puede dar pie a guerras comerciales (Schiff y Winters, 2003).

${ }^{34}$ Diferencias por ejemplo, en el acceso a mercados, en la determinación de las normas de origen, en la prevalencia de unos regímenes frente a otros, etc.

${ }^{35}$ El fundamento del marco teórico de la integración económica se construyó sobre dos estudios, uno de la década de 1950, la Teoría de las uniones aduaneras de Jacob Viner, economista canadiense de origen rumano, fundador de la Escuela de Chicago, y otro de la década de 1980, la Teoría de la integración económica, de Béla Alexander Balassa, economista húngaro, profesor renombrado de la Universidad Johns Hopkins y consultor del Banco Mundial.
} 
unión tarifaria, en el fisco del país por el que ingresa, mientras que en la unión aduanera, independientemente del lugar por el que ingresa, va a parar a la hacienda común (Dromi et al., 1995). Además, la unión tarifaria necesita un altísimo grado de cooperación y articulación de las aduanas nacionales para evitar costos adicionales, mientras que en la unión aduanera la aduana supranacional es la que toma las decisiones y las aduanas nacionales son meros ejecutores de la misma.

Consolidada una unión aduanera, aparte de la eliminación de aranceles y barreras arancelarias, la definición de un arancel externo común y la creación de un ente supranacional de aduana, se liberan el capital y el trabajo. A partir de este estamento, prácticamente estaríamos frente a la fusión de los espacios económicos nacionales ${ }^{36}$, donde se da libertad plena a bienes, servicios, capital y trabajo, por lo que es imprescindible un altísimo grado de cooperación para armonizar políticas macroeconómicas y sectoriales ${ }^{37}$.

Si a un mercado común, donde operan las libertades de bienes, servicio, capital y trabajo se le suma la entrega - parcial o plena- de competencias macroeconómicas y sectoriales (política monetaria y fiscal) a los entes decisorios de carácter supranacional, se constituye una unión económica. Estos estamentos, que configuran la integración económica, necesariamente son discriminatorios frente a los terceros ajenos a la zona, toda vez que las libertades otorgadas se fundamentan en el origen, sea de los bienes, servicios, capital y trabajadores ${ }^{38}$.

Por su parte, los acuerdos comerciales pueden ser orientados hacia el interior o hacia el exterior, en el primer caso estaríamos ante lo que se denominó regionalismo cerrado, donde con el objeto de sustituir las importaciones de países ajenos a la zona, se promueve la industrialización, el proteccionismo y el incremento de barreras arancelarias y no arancelarias con el fin de proteger y promover la industria intra zonal. En sentido contrario, el regionalismo abierto promueve el establecimiento de acuerdos de comercio orientados al exterior, abiertos a las competencias internacionales e inmerso en el sistema multilateral

\footnotetext{
${ }^{36}$ En el asunto Shull, el Tribunal de Justicia de las Comunidades Europeas, en su sentencia del 5 de mayo de 1982, definió al mercado común como la fusión de los mercados nacionales en un mercado único que funcione en condiciones lo más similares posibles a las de un verdadero mercado interior. ${ }^{37}$ Una de las grandes dificultades por las que atraviesa la Unión Europea para superar la crisis es que en materia monetaria, las competencias transferidas al Banco Central Europeo no son plenas y de ahí que haya que concertar decisiones con los gobiernos nacionales. El denominado Pacto Fiscal, formalmente Tratado de Estabilidad, Coordinación y Gobernanza en la Unión Económica y Monetaria, es un acuerdo firmado el 2 marzo de 2012 por 25 Estados miembros que contiene un conjunto de 'reglas de oro', que por su carácter vinculante garantizarían el principio de equilibrio presupuestario. ${ }^{38}$ La lógica progresiva descrita e inherente a los procesos de integración, permitiría entender estos estamentos como secuenciales, es decir que se transitarían una a una las etapas. Sin embargo, en la práctica esto no es necesariamente así, de hecho las paradigmáticas comunidades europeas empiezan por la unión tarifaria (de consumidores) antes de liberar bienes y servicios (González, Gutiérrez y Martín, 2010).
} 
de comercio (Pereyra, 2007). No obstante, como precisan Schiff y Winters (2003), una economía perfectamente abierta no podría discriminar a terceros de la manera como lo exige cualquiera de los estamentos de integración económica que venimos explicando ${ }^{39}$.

Tinbergen (1954) acuñó las expresiones de integración 'negativa' y 'positiva', que corresponden a la integración de carácter superficial y profundo, respectivamente. La primera de ellas comprende la supresión y limitación de las políticas en la zona, a diferencia de los esfuerzos positivos por coordinarlas (trato nacional). Por su parte, la integración 'profunda', ya en palabras de Lawrence y Litan (1990), se refiere más bien a los esfuerzos destinados a una integración más trascendental. Schiff y Winters (2003) coinciden en que la expresión se puso en circulación refiriéndose a acuerdos tales como el de la Unión Europea, con el propósito de lograr una unión económica que creara instituciones supranacionales para conseguir dicho objetivo ${ }^{40}$.

Si bien la Alianza se anuncia como una integración profunda, hasta el momento -el recién suscrito Protocolo Adicional al Acuerdo $\mathrm{Marco}^{41}$ - ha configurado una zona de libre comercio, sujeta a procesos ratificatorios en los cuatro países miembros, en la cual una vez, en vigor eliminarán y/o disminuirán significativamente sus aranceles y dejarían establecidos los estándares de las barreras no arancelarias. En todo caso esto ya era una realidad imperfecta fundamentada en los acuerdos bilaterales y/o multilaterales que previamente pactaron sus miembros.

La liberalización parcial de bienes y servicios y sus asuntos trasversales que definen los estándares de las barreras no arancelarias se fundamenta en los acuerdos de libre comercio de Chile con México de 1998; de Chile con Colombia y Perú en 2006; de México con Colombia en 1995, con Chile en 1999 y con Perú en 2012; y el existente entre Perú y Colombia en el marco de la Comunidad Andina. Estamos por tanto frente a varias zonas de libre comercio que podrían presentar obstáculos administrativos, en acceso a mercados, en la determinación de normas de origen entre sí y que además, en el caso de la configurada por la Comunidad Andina y que rige para Perú y Colombia, por previsión

\footnotetext{
${ }^{39}$ Schiff y Winters (2003) nos recuerdan que el regionalismo abierto fue una idea de la década de 1990 que se concibió para describir las aspiraciones originales de la APEC y transmitir su plena coherencia con los objetivos multilaterales. Lo anterior se explica porque la APEC es un foro, no un acuerdo regional de integración que como tal, necesita discriminar a terceros.

${ }^{40}$ Canovas (2002) al estudiar las comunidades europeas, entendía a la integración como un proceso gradual, donde el éxito dependía, tanto de la transferencia de soberanía a los entes supranacionales, como de la actitud de las masas frente al proceso.

41 "Las Partes, de conformidad con lo dispuesto en el Artículo XXIV del Acuerdo General sobre Aranceles Aduaneros y Comercio de 1994 y el Artículo V del Acuerdo General sobre el Comercio de Servicios, que forman parte del Acuerdo de Marrakech por el que se establece la Organización Mundial del Comercio, establecen una zona de libre comercio". Artículo 1.1 del Protocolo Adicional al Acuerdo Marco de la Alianza del Pacífico, suscrito en Cartagena, Colombia, el 10 de febrero de 2014.
} 
de sus tratados constitutivos, prevalece, incluyendo su régimen de propiedad intelectual y su imperfecto arancel externo. El Protocolo Adicional, incluso cuando entre en vigor, no soluciona del todo estas dificultades, toda vez que se conservan unos requisitos específicos de origen que se pactaron en el anexo 4.2.

Costa Rica, Panamá y Guatemala, observadores y aspirantes a integrarse en la Alianza, harían más complejos los obstáculos administrativos derivados de los acuerdos perfeccionados y por perfeccionar, toda vez que ellos también pertenecen a un régimen prevalente, en su caso, el del Sistema de Integración Centroamericano. Así no solo serán Perú y Colombia los que deberán resolver su doble militancia ${ }^{42}$.

Queda por resolver si la integración profunda pretendida implica liberalización no solo de bienes y servicios, sino también de capital y personas, de ser así, de acuerdo con el marco teórico de la integración, necesariamente se fundamentaría en entes supranacionales decisorios que impongan patrones de conducta y administren el espacio económico que resulta fusionado para garantizar la plena liberalización de las cuatro libertades referidas. De lo contrario, es condenar la eficacia del proceso a la revalidación política permanente de los Estados miembros y someter las decisiones adoptadas a mecanismos no automáticos de incorporación en las legislaciones internas ${ }^{43}$.

La razón de integrarse define el segundo objetivo que se traza la Alianza: la constitución de un marco vinculante que les facilite un acceso más seguro a los mercados más importantes, lo que estimularía "un mayor crecimiento, desarrollo y competitividad de las economías de las partes" ${ }^{44}$. Adicionalmente, cierran este objetivo resaltando la pretensión de lograr un mayor bienestar, la superación de la desigualdad socioeconómica y la inclusión social de sus habitantes.

El tercer y último objetivo tiende a convertir el área de integración regional constituida en una plataforma de articulación política, de integración económica y comercial, de proyección al mundo, con especial énfasis al Asia Pacífico ${ }^{45}$. Objetivo que para cristalizarse, implica el cambio de la práctica regional, toda vez que ninguna experiencia latinoamericana

\footnotetext{
${ }^{42}$ La doble militancia no se soluciona precisando que el régimen de solución de diferencias previsto en el capítulo 17 del Protocolo adicional "no aplicará a las diferencias que surjan entre la República de Colombia y la República del Perú respecto de las normas que conforman el Ordenamiento Jurídico de la Comunidad Andina", tal como se prevé en el pie de página del artículo 17.3.

${ }^{43}$ No obstante, el objetivo no está definido. El literal a. donde se menciona, lo condiciona a futuros consensos que solo podrán expresarse mediante marcos regulados vinculantes, esto es al perfeccionar tratados internacionales. Literal a. del numeral $1^{\circ}$ del artículo 3 del Tratado de Paranal del 6 de junio de 2012, constitutivo de la Alianza del Pać́fico.

${ }^{44}$ Literal b. del numeral $1^{\circ}$ del artículo 3 del Tratado de Paranal del 6 de junio de 2012, constitutivo de la Alianza del Pacífico.

${ }^{45}$ Literal c. del numeral $1^{\circ}$ del artículo 3 del Tratado de Paranal del 6 de junio de 2012, constitutivo de la Alianza del Pacífico.
} 
de integración regional o subregional ha logrado negociar en bloque o incrementado su poder de negociación, siempre termina por reinar el unilateralismo (Tremolada, 2013 c).

\section{La Alianza del Pacífico y sus desarrollos}

El Tratado constitutivo de la Alianza previó en el literal a. del numeral $2^{\circ}$ del artículo 3 , la liberalización del intercambio comercial de bienes y servicios, con miras a consolidar una zona de libre comercio. Adicionalmente, el literal c. del mismo numeral propuso desarrollar acciones de facilitación del comercio y asuntos aduaneros, de ahí que los ejes centrales del recién suscrito Protocolo Adicional pactara capítulos en materia de acceso a mercados, reglas de origen, facilitación de comercio y cooperación aduanera, medidas sanitarias y fitosanitarias, obstáculos técnicos al comercio, contratación pública, comercio transfronterizo de servicios, inversión, servicios financieros, servicios marítimos, comercio electrónico, telecomunicaciones, transparencia y solución de diferencias. Adicionalmente, el Protocolo Adicional profundizó en materia de aranceles, ahondando en las condiciones de acceso bilateral existente al liberalizar 90\% de líneas arancelarias ${ }^{46}$.

Con respecto a la libre circulación de capitales y la promoción de las inversiones previstas en el literal b. del numeral $2^{\circ}$ del artículo 3 del Tratado de Paranal, las partes quieren por un lado, que el área constituida sea un destino interesante para la inversión y el comercio de servicios y por el otro, aumentar los flujos de inversión y de comercio de servicios entre ellos y con el resto del mundo.

El capítulo 10 acordado en el Protocolo Adicional no presentó mayores dificultades en la negociación, toda vez que se fundamentó en los capítulos de inversión contenidos en los tratados bilaterales de libre comercio que existen entre los miembros de la Alianza y en el caso de Perú y Colombia, se basó en el Acuerdo Autónomo de Promoción y Protección Recíproca de Inversiones ${ }^{47}$. Además como bloque, los miembros potencian su atractivo recordando constantemente -a propios y extraños-, que en conjunto, son la octava economía y la séptima potencia exportadora a nivel mundial. En América Latina y el Caribe, los cuatro representan 36\% del PIB, concentran 50\% del comercio total y atraen 41\% de los flujos de inversión extranjera directa que llegan a la región. Adicionalmente, con una población joven y fuerza de trabajo calificada, totalizan 212 millones de personas con un PIB per cápita promedio de 10.000 dólares $^{48}$.

\footnotetext{
${ }^{46}$ Véase Protocolo Adicional al Acuerdo Marco de la Alianza del Pacífico capítulos 3 al 17.

47 Véanse sitios Web del Ministerio de Comercio, Industria y Turismo de Colombia, la Agencia de la Promoción de la Inversión Privada en Perú, la Dirección General de Relaciones Económicas Internacionales de Chile y ProMéxico, Inversión y Comercio.

${ }^{48}$ Cifras a 2012 con información de la OMC y el FMI tomadas del sitio web de la Alianza del Pacífico,. En http://alianzapacifico.net/que_es_la_alianza/valor-estrategico/
} 
Por su parte, el literal d. del numeral $2^{\circ}$ del artículo 3 del Tratado de Paranal se refiere a la promoción de la cooperación entre las autoridades migratorias y consulares para facilitar el movimiento de personas y el tránsito migratorio. Sin embargo se prioriza "el movimiento de personas de negocios y la facilitación del tránsito migratorio incluyendo la cooperación migratoria y consular policial”. Se vienen discutiendo opciones de facilitación que se traducen en visados especiales y esquemas de agilización de ingreso para personas de negocios. En esta materia, solo hay dos avances significativos: por un lado la eliminación de la exigencia de visas para nacionales de Colombia y de Perú que quieran viajar a México; de esta manera el gobierno mexicano brinda a todos los nacionales de países miembros de la Alianza un fácil acceso a su territorio que incluye personas que no realizarán actividad remunerada. Y por el otro, el anunció de Perú sobre la supresión de visas para personas de negocios de Chile, Colombia y México hasta 183 días, siempre que realicen una actividad no remunerada ${ }^{49}$.

En este campo, basados en la práctica regional, no somos muy optimistas, solo pensando en un proceso de integración como el Andino, que evidentemente es profundo y del que Perú y Colombia son partes, solo se ha podido aprobar por el ente supranacional, la admisión e ingreso de ciudadanos en calidad de turistas mediante la sola presentación de uno de los documentos nacionales de identificación, válido y vigente, para permanencias de hasta noventa días prorrogables por un período más ${ }^{50}$. Derecho que en la práctica, no solo no se difunde sino que en el las autoridades migratorias fijan arbitrariamente los tiempos de permanencia. Incluso se han modificado unilateralmente los requisitos de admisión e ingreso ${ }^{51}$.

En todo caso, tanto en la Alianza como en la Comunidad Andina, no se evidencia la posibilidad de liberar el factor trabajo, pese a que se trata de una libertad indispensable para la integración profunda, si entendemos está en los términos en que se generó su expresión.

Compartir sedes diplomáticas es una experiencia inédita en la región, fundamentada en acuerdos específicos entre los países miembros de la Alianza así, los cuatro países comparten la sede en Ghana; Colombia y Perú, y hacen lo propio en Vietnam, Chile y Colombia; comparten sedes en Marruecos, Argelia, Azerbaiyán y en la Misión

\footnotetext{
${ }^{49}$ Sitio Web de la Alianza del Pacífico, en http://alianzapacifico.net/ movimiento-de-personas//

${ }^{50}$ Decisión 503 del 22 de junio de 2001, expedida por el Consejo Andino de Ministros de Relaciones Exteriores.

${ }^{51}$ En un entendimiento de los gobiernos de Ecuador y Colombia, se permitió que a los nacionales colombianos que viajen a Ecuador se les exigiera adicionalmente el certificado de antecedentes penales y de policía. Posteriormente el gobierno de Ecuador, después del bombardeo de Colombia en Sucumbíos, retoma la medida y además exige que el certificado de antecedentes penales y de policía se presente con apostilla.
} 
Diplomática en la Organización para la Cooperación y el Desarrollo Económico (OCDE) y próximamente, lo harán en Singapur Colombia y México ${ }^{52}$.

Por último, los literales e y f del mismo numeral y artículo que venimos estudiando, proponen primero, coordinar la prevención y contención de la delincuencia organizada transnacional para fortalecer las instancias de seguridad pública y de procuración de justicia que no tienen ningún desarrollo conocido y segundo, contribuir con medidas mediante el desarrollo de mecanismos de cooperación.

Cuatro proyectos de cooperación se vienen desarrollando. Primero una plataforma de movilidad estudiantil y académica que promueva el intercambio de estudiantes de pregrado y posgrado, así como de docentes universitarios e investigadores en instituciones de educación superior -lo que durante 2013 significó 228 becarios de pregrado y treinta de posgrado-. Segundo, el proyecto de investigación científica en materia de cambio climático que intercambia experiencias y avances en la investigación, monitorea oportunidades de colaboración, explora la aplicación de conocimiento científico y desarrollo de capacidades y trabaja para producir conocimiento de aplicación a políticas públicas.

En tercer lugar, se coopera para generar sinergias que contribuyan al mejoramiento de la competitividad de las micro, pequeñas y medianas empresas, fortalecimiento de la institucionalidad y la gestión mediante un intercambio de conocimientos y experiencias -se trabaja a través de cuatro talleres: competitividad empresarial, desarrollo empresarial, monitoreo y evaluación de impacto de programas y proyectos MIPYMES-, así como mecanismos de financiamiento.

Finalmente, en mayo de 2013 se suscribió el “Acuerdo para el Establecimiento del Fondo de Cooperación” que se encuentra en proceso de ratificación, el cual a través de aportaciones financieras equitativas de las partes que lo conforman, permitirá financiar la ejecución de proyectos y acciones de cooperación en las áreas de medio ambiente y cambio climático; innovación, ciencia y tecnología; micro, pequeñas y medianas empresas; y desarrollo social en las diferentes modalidades definidas en el propio Acuerdo ${ }^{53}$.

\section{La Alianza del Pacífico y su estructuración}

En la práctica, sin que el Tratado constitutivo lo prevea, los presidentes de los cuatro países entienden que conforman el máximo órgano de decisión del proceso; configurando

\footnotetext{
${ }^{52}$ Sitio Web de la Alianza del Pacífico, en http://alianzapacifico.net/embajadas-compartidas-entrechile-colombia-mexico-y-peru-uno-de-los-logros-de-la-alianza-del-pacifico/

${ }^{53}$ Sitio Web de la Alianza del Pacífico, consultado el 23 de febrero de 2014, en http://alianzapacifico.net/cooperacion/
} 
la misma lógica -aunque no institucionalizada- que en los demás procesos de integración regional personificó y jerarquizó la integración y que contribuye poco a sus desarrollos ${ }^{54}$.

Los ministros de relaciones exteriores y los ministros responsables de comercio exterior o sus designados, conforman el Consejo de Ministros, un órgano encargado de adoptar decisiones que desarrollan los objetivos y acciones del Tratado y de las Declaraciones Presidenciales. A su vez, vela por el cumplimiento y aplicación de las decisiones, evalúa resultados, aprueba actividades y define lineamientos políticos en su relación con terceros, establece grupos de trabajo, sus propias reglas y adopta las medidas necesarias para la consecución de objetivos ${ }^{55}$. El Consejo se reunirá ordinariamente una vez al año y extraordinariamente a petición de alguno de los Estados miembros. Para sesionar se necesita la representación de todos las partes. Todas las decisiones y/o acuerdos se deben adoptar por consenso y serán parte integrante del ordenamiento jurídico de la Alianza. Podrán contemplar diferentes modalidades para la consecución de los objetivos ${ }^{56}$.

Un Grupo de Alto Nivel (GAN) integrado por los viceministros de relaciones exteriores y de comercio exterior de los países miembros, se creó con la Declaración Presidencial de Lima el 28 de abril de 2011. Este supervisa los avances de los grupos técnicos, evalúa nuevas áreas en las cuales se pueda seguir avanzado y prepara propuestas para la proyección y relacionamiento externo con otros organismos o grupos regionales. El grupo podrá ser convocado por el Consejo de Ministros cuando lo estime necesario.

A la Presidencia Pro Tempore de la Alianza del Pacífico le corresponde la organización de las cumbres presidenciales, la coordinación de las reuniones del Consejo de Ministros y del GAN y el registro de actas. Se ejerce de manera sucesiva por cada uno de los Estados miembros, en orden alfabético, por períodos anuales que inician en enero. Además, ejercerá las atribuciones que le confiera expresamente el Consejo de Ministros y pondrá a consideración de este los programas de actividades y por encargo de los Estados, representará a la Alianza ${ }^{57}$.

Existen unos grupos y subgrupos técnicos, que aunque el Tratado constitutivo no menciona, están compuestos por servidores públicos de los cuatro países miembros, cuya función es negociar disciplinas pactadas en el marco de la Alianza.

\footnotetext{
${ }^{54}$ El sitio web de la Alianza resalta esta personificación y jerarquización considerando la reunión de los presidentes como órgano. Sitio Web de la Alianza del Pacífico, en http://alianzapacifico.net/ que_es_la_alianza/estructura-y-organigrama/

${ }^{55}$ Artículo 4 del Tratado de Paranal del 6 de junio de 2012, constitutivo de la Alianza del Pacífico. ${ }^{56}$ Artículos 5 y 6 del Tratado de Paranal del 6 de junio de 2012, constitutivo de la Alianza del Pacífico.

${ }^{57}$ Artículo 7 del Tratado de Paranal del 6 de junio de 2012, constitutivo de la Alianza del Pacífico.
} 


\section{Estructura y organigrama de la Alianza del Pacífico}

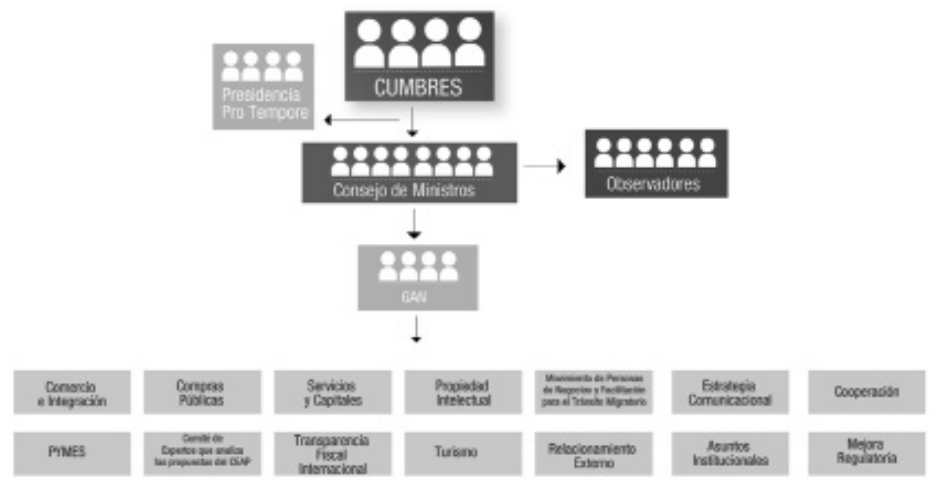

Fuente: http://alianzapacifico.net/que_es_la_alianza/estructura-y-organigrama/

Si se tiene en cuenta que el Tratado constitutivo solo menciona al Consejo de Ministros como único órgano con competencias híbridas entre lo ejecutivo y lo administrativo y que encarga anualmente la Presidencia pro témpore al servicio exterior de cada Estado miembro, es prematuro hacer un análisis de la estructura organizativa. No obstante, la composición y forma de adoptar decisiones del Consejo nos permite inferir un régimen intergubernamental de cooperación política que no se correspondería con la pretendida construcción de un área de integración profunda ${ }^{58}$.

En todo caso, los desarrollos del Tratado constitutivo, del Protocolo Adicional y las decisiones del Consejo de Ministros y otros acuerdos adoptados son parte integrante del ordenamiento jurídico de la Alianza del Pacífico. De esta manera, se está configurando un conjunto de normas y actos jurídicos que regulan las conductas de los Estados entre sí y de estos con organismos donde se procura potenciar la cooperación entre las partes para facilitar la obtención de los fines propuestos en el Tratado constitutivo, mejorar sus relaciones recíprocas y fortalecer su posición conjunta frente a los Estados ajenos al área formada. Se trataría de un derecho de la integración regulado por el derecho internacional general, distinto del denominado derecho comunitario (Pizzolo, 2002) ${ }^{59}$.

\section{La Alianza del Pacífico constituye una organización internacional}

Una entidad interestatal, establecida por un tratado internacional, dotada de órganos permanentes propios e independientes, encargados de gestionar intereses colectivos y capaces

\footnotetext{
${ }^{58}$ Los intergubernamentalistas liberales que como Moravcsik consideran que un régimen intergubernamental de cooperación política negociada sería exitoso, no tienen un solo ejemplo que lo soporte, en Oyarzún Serrano (2008).

${ }^{59}$ Nos referimos al derecho comunitario que señala un tipo de proceso de integración determinado por principios diversos que constituye un autónomo y verdadero ordenamiento jurídico (Pizzolo, 2002).
} 
de expresar una voluntad jurídica distinta de la de sus miembros, es lo que conocemos como organización internacional. Estas organizaciones pueden tener un carácter universal o restringido. Las universales se fundamentan en el principio de inclusión, esto es en la posibilidad de que los Estados cooperen entre todos. Las de carácter restringido se basan en el principio de la exclusión, porque la cooperación se reduce a un número limitado de Estados, toda vez que obedecen a un orden espacial, este es el caso de las organizaciones regionales, subregionales e incluso de las intercontinentales. De acuerdo con esta clasificación la Alianza del Pacífico, siempre que goce de personalidad jurídica internacional, estaría configurando una organización internacional restringida entre lo regional e intercontinental, toda vez que pretende fortalecer los diferentes esquemas de integración en América Latina, además de mantener una proyección hacia la región de Asia-Pacífico ${ }^{60}$.

Las organizaciones interestatales también se clasifican según las materias objeto de cooperación, se puede distinguir entre organizaciones con competencia general, donde el nivel de cooperación depende del interés de los Estados miembros (Naciones Unidas) y las organizaciones con competencias especiales, donde las capacidades son restringidas a sectores previamente definidos como el militar, económico o social. El criterio de clasificación que responde al método de cooperación, como explica Pastor Ridruejo (2010), es más amplio en el entendido de que estas organizaciones se subdividen en las de coordinación, control, operacionales e integración. No se puede entender la clasificación en un sentido excluyente, en la actualidad las organizaciones poseen un carácter híbrido, compartiendo características comunes. De hecho, la Alianza evidencia una competencia especial, referida al sector económico (área de integración profunda para avanzar progresivamente hacia la libre circulación de bienes, servicios, capitales y personas), con características de coordinación e integración (construida, de manera participativa y consensuada) ${ }^{61}$.

El criterio del reparto de competencias también permite clasificar a las organizaciones de interestatales. Podemos distinguir entre aquellas en las cuales los Estados miembros han cedido sus competencias soberanas y las que se consideran como una simple cooperación para coordinar y desarrollar intereses comunes (Pallares Bossa, 2004). Así, en las que opera una cesión de competencias de los Estados miembros a los órganos comunes, se caracterizan por suponer la atribución de poderes estatales a unos órganos independientes que tienen la posibilidad de pronunciarse, sea por mayoría y/o unanimidad, al tiempo que las decisiones que adopten podrán tener, en determinadas ocasiones, autoridad directa e inmediata en los órganos jurídicos nacionales (Diez de Velasco, 2009) ${ }^{62}$.

\footnotetext{
60 Preámbulo del Tratado de Paranal del 6 de junio de 2012, constitutivo de la Alianza del Pacífico. ${ }^{61}$ Véanse, artículos $3^{\circ}$ y $1^{\circ}$-en ese orden- del Tratado de Paranal del 6 de junio de 2012, constitutivo de la Alianza del Pacífico.

62 Los ejemplos más representativos en este sentido los evidenciamos en los ordenamientos jurídicos de la Unión Europea, Sistema de Integración Centro Americano SICA y Comunidad Andina.
} 
En el del Tratado de Paranal constitutivo de la Alianza, no evidenciamos cesión de competencias, por el contrario se enfatiza en la voluntad de constituirla como un espacio de concertación y convergencia, que se hará de manera progresiva, participativa y consensuada ${ }^{63}$. Estamos pues, frente a una simple cooperación para coordinar y desarrollar intereses comunes entre los miembros ${ }^{64}$.

Una última clasificación que analizaremos es la que atiende el criterio de la jerarquía. Así, las organizaciones internacionales podrían clasificarse en supranacionales o intergubernamentales. Las supranacionales cuentan con poder decisorio que vincula a los Estados sin su consentimiento y con efecto directo sobre sus nacionales, por el otro lado, las organizaciones intergubernamentales requieren consentimiento de los Estados para vincularlos (Urueña, 2008).

El Tratado de Paranal, por un lado, deja claro que las decisiones le competen al Consejo de Ministros y estas, como otros acuerdos, se adoptarán por consenso y por otro lado, que todas sus normas serán parte integrante de su ordenamiento jurídico ${ }^{65}$. Sin embargo, no menciona el mecanismo de incorporación de estas decisiones y mucho menos hace referencia a la aplicación y efecto de las mismas. Así, sumado al énfasis que se hace en el texto a la cooperación progresiva, participativa y consensuada, no nos quedan dudas que estaríamos frente a una organización intergubernamental en la que sus decisiones requerirán consentimiento de los Estados para vincularlos.

\section{La personalidad jurídica internacional de la Alianza del Pacífico}

Las organizaciones internacionales actúan en dos dimensiones, al interior de sus Estados miembros, como cuando adoptan normas y al exterior cuando se relacionan con terceros Estados y otras organizaciones internacionales ${ }^{66}$. Esta doble dimensión plantea el problema de su personalidad jurídica no solo en el interior de los Estados miembros, sino también respecto al derecho internacional. En otras palabras, tienen capacidad para ser titulares de derechos y obligaciones conforme al derecho internacional y de establecer relaciones jurídicas internacionales con terceros Estados y otras organizaciones.

A partir de 1949, con la opinión consultiva de la Corte Internacional de Justicia en el asunto de la reparación de daños sufridos al servicio de las Naciones Unidas, no se discute la posibilidad de que las organizaciones internacionales gocen de personalidad

${ }^{63}$ Tampoco existe cesión de competencias en el Mercosur, ALBA, Unasur y CELAC.

${ }^{64}$ Véase Preámbulo y artículo $3^{\circ}$, del Tratado de Paranal del 6 de junio de 2012, constitutivo de la Alianza del Pacífico.

${ }^{65}$ Véase, artículos $4^{\circ}, 5^{\circ}$ y $6^{\circ}$, del Tratado de Paranal del 6 de junio de 2012, constitutivo de la Alianza del Pacífico.

${ }^{66}$ Las organizaciones internacionales tienen un rol relevante en el reforzamiento de la cooperación internacional, permitiéndose administrar programas entre sus miembros (Senarclens, 1993). 
jurídica al ser consideradas como sujetos del ordenamiento internacional. Pero no todas las organizaciones internacionales son explícitas en su tratado constitutivo sobre su carácter de persona jurídica, dependiendo muchas veces del reconocimiento propio y/o de terceros. De ahí y fundamentados en Urueña (2008), analizaremos tres escuelas que nos sirven para este propósito:

1. La escuela atributiva, que considera que las organizaciones internacionales gozan de personalidad jurídica internacional siempre que esta haya sido atribuida de manera expresa por los Estados miembros, es decir que debe existir una estipulación en el contenido del respectivo tratado constitutivo ${ }^{67}$.

2. Contrariamente, existe la personalidad jurídica objetiva, que sin necesidad de la mención expresa en el tratado constitutivo, supone que las organizaciones contarán con personalidad jurídica en la medida en que estas cuenten con un órgano que expresa su voluntad de manera independiente de la de los Estados miembros. Entendemos que se fundamenta en la capacidad del órgano que, si se creó de tal manera, puede expresar la voluntad de la organización de forma autónoma a los Estados que la componen, estos le atribuyeron la personalidad jurídica de manera tácita ${ }^{68}$.

3. Además, existe la escuela subjetiva que se sostiene que la personalidad jurídica se deriva de la voluntad de los Estados. Así, esta puede ser reconocida por los Estados miembros y/o por terceros ${ }^{69}$.

A nuestro entender la existencia del Consejo de Ministros, como órgano al que se le ha encomendado el cumplimiento de tareas específicas ${ }^{70}$, la existencia de obligaciones de los miembros con respecto al desarrollo de los objetivos de la organización ${ }^{71}$, el

\footnotetext{
${ }^{67}$ Por ejemplo, el artículo 6 del Tratado Constitutivo de la Comunidad Europea del Carbón y del Acero precisaba que "en las relaciones internacionales, la Comunidad gozará de la capacidad jurídica necesaria para el ejercicio de sus funciones y la consecución de sus fines".

68 Muchos consideraron que este fue el caso de la Unión Europea entre 1993 y 2009, toda vez que el Tratado de la Unión Europea no hacía la mención expresa. Sin embargo, las delegaciones de la Unión Europea en el mundo solo aparecen como tal a partir del $1^{\circ}$ de diciembre de 2009, fecha en que entró en vigor el Tratado de Lisboa y este le otorga expresamente la personalidad jurídica a la Unión, antes de eso lo que existían eran delegaciones de la Comisión Europea.

${ }^{69}$ Terceros Estados y otras organizaciones internacionales, entre los años 1993 y 2009, no dudaban en referirse a la Unión Europea como una organización con personalidad jurídica internacional, pese a que cuando se relacionaban con esta, la contra parte que suscribía los acuerdos por el lado europeo siempre era alguna de sus comunidades que sí contaban con la personalidad jurídica expresada en sus tratados constitutivos.

${ }^{70}$ Numeral $2^{\circ}$ del artículo 4, del Tratado de Paranal del 6 de junio de 2012, constitutivo de la Alianza del Pacífico.

${ }^{71}$ Numeral $2^{\circ}$ del artículo 3, del Tratado de Paranal del 6 de junio de 2012, constitutivo de la Alianza del Pacífico.
} 
Acuerdo para el Establecimiento del Fondo de Cooperación de la Alianza del Pacífico ${ }^{72}$ y la eventual posesión de capacidad jurídica, privilegios e inmunidades que tendrían sus agentes en el territorio de los miembros, no nos dejarían duda acerca de la personalidad jurídica de la Alianza del Pacífico, de conformidad con el criterio de la personalidad jurídica objetiva. Adicionalmente, no descartaríamos el criterio subjetivo, toda vez que la personalidad jurídica derivaría de la voluntad de los Estados, que conforme a su tratado constitutivo y a las declaraciones de sus presidentes ${ }^{73}$, le definen a la Alianza la promoción de iniciativas y lineamientos de acción sobre temas de interés regional o internacional, es decir, actuando como un ente autónomo ${ }^{74}$.

En todo caso, el desarrollo de los objetivos en una organización internacional se fundamenta en un cuerpo normativo que constituye su orden jurídico, comprendido por el derecho constitutivo u originario (tratados, protocolos y anexos) y por el derecho derivado o secundario que producen sus órganos. Hasta el momento, el ordenamiento jurídico de la Alianza está compuesto por el Tratado de Paranal, el Protocolo Adicional - una vez entre en vigor-, las decisiones del Consejo de Ministros y las declaraciones presidenciales.

\section{Reiterando conclusiones}

Asia Oriental, esto es China, Corea del Norte, Corea del Sur, Japón, Mongolia y Taiwán, junto con el Sudeste Asiático comprendido por Birmania, Brunéi, Camboya, Filipinas, Indonesia, Laos, Malasia, Singapur, Tailandia, Timor Oriental y Vietnam; y en Oceanía, Australia, Nueva Zelandia y las islas de Nueva Guinea descartando Melanesia, Micronesia y Polinesia es el horizonte de países donde Colombia y sus socios de la Alianza quieren mejorar su inserción y que en este estudio englobamos como Asia-Pacífico.

En la región Asia-Pacífico hay una tensión latente entre las dos negociaciones en ciernes, por un lado la del RCEP, impulsada por China, que ofrece consideraciones más generosas, compatibles con las normas OMC, que se centran en reformas estructurales internas necesarias para la aplicación de la liberalización, donde se negocia un enfoque simplificado y armonizado de las normas de origen que permite la acumulación y reduce los costos de transacción y de tiempo, frente al TPP, liderado por Estados Unidos, en el que se negocian exigentes requerimientos de propiedad intelectual y protección de las inversiones.

\footnotetext{
72 Véase el Sitio Web de la Alianza del Pacífico, en http://alianzapacifico.net/

73 Véase Declaraciones presidenciales de Lima, Mérida, Paranal, Cádiz, Santiago y Cali. En Sitio Web de la Alianza del Pacífico, en http://alianzapacifico.net/

${ }^{74}$ No obstante, en lo que concierne a la voluntad prevista en el tratado, podríamos estar forzando las reglas de interpretación de tratados internacionales. Véase, parte III Observancia, aplicación e interpretación de los tratados, en la Convención de Viena sobre el derecho de los tratados del 23 de mayo de 1969.
} 
El TPP próximo a cerrarse en el que ya es socio Chile y está siendo negociado por Perú y México, favorecería la ya fuerte inserción de los socios y competidores de Colombia en Asia-Pacífico, socios que ya nos vienen desplazando considerablemente en participación de mercado, en gran medida por el nutrido número de preferencias que tienen pactadas con los países de esta región.

El RCEP que recién va a celebrar su cuarta ronda de negociación, configuraría un bloque económico de 3.000 millones de personas, con un PIB combinado de $\$ 17$ billones de dólares, que representaría 40 por ciento del comercio mundial. Por su parte, el TPP constituirá un área de libre comercio de 790 millones de personas que concentraría la tercera parte del comercio global y un PIB mundial cercano a $40 \%$.

Para Colombia, consciente de las potencialidades que brinda la región Asia-Pacífico, en la que nuestros socios de la Alianza nos vienen desplazando, encontró con la propia Alianza un medio de acortar brechas en el desplazamiento y tiempos de negociación de preferencias -que a su entender ahora podrán darse bloque a bloque-, mejorando su participación en ese mercado.

Los acuerdos económicos, comerciales y de integración vigentes entre México, Perú, Chile y Colombia, fundamentan la economía abierta que viene constituyendo la Alianza del Pacífico, sin embargo, todo acuerdo regional de integración de carácter económico -en virtud a las normas de origen- discrimina. Así lo hacen los acuerdos comerciales existentes y así lo hará la propia Alianza.

Homologar normas de origen entre todos los miembros es un difícil reto que se alcanzó parcialmente en el recién firmado Protocolo Adicional y que por ahora solo se refiere a los acuerdos entre estos, sin tener en cuenta las obligaciones económicas que tenga cada uno con terceros. En todo caso, tanto en el Tratado Constitutivo de la Alianza como en el Protocolo Adicional, señalan su respeto por las obligaciones con terceros. No obstante, mientras se trabaja en la homologación de tratados, se puede presentar superposición de obligaciones que pueden llegar a generar responsabilidad internacional.

Se pretende construir un área de integración profunda para avanzar progresivamente hacia la libre circulación de bienes, servicios, capitales y personas. Si entendemos que se trata de la liberalización de estos factores, necesariamente se fundamentaría en entes supranacionales decisorios que impongan patrones de conducta y administren el espacio económico que resulta fusionado para garantizar la plena liberalización de las cuatro libertades referidas. De lo contrario, se condena la eficacia del proceso a la revalidación política permanente de los Estados miembros y se someten las decisiones adoptadas a mecanismos no automáticos de incorporación en las legislaciones internas.

La Alianza tiende a convertir su área de integración regional en una plataforma de articulación política, de integración económica y comercial y de proyección al mundo, con especial énfasis al Asia-Pacífico, incrementado así su poder de negociación. Sin 
embargo, ninguna experiencia latinoamericana de integración regional o subregional ha logrado negociar en bloque, siempre termina por reinar el unilateralismo.

El Protocolo Adicional, en trámite de ratificación, negoció capítulos en materia de acceso a mercados, reglas de origen, facilitación de comercio y cooperación aduanera, medidas sanitarias y fitosanitarias, obstáculos técnicos al comercio, contratación pública, comercio transfronterizo de servicios, inversión, servicios financieros, servicios marítimos, comercio electrónico, telecomunicaciones, transparencia y solución de diferencias. Asímismo, profundizó en materia de aranceles, ahondando en las condiciones de acceso bilateral existente al liberalizar 90\% de líneas arancelarias. Sin embargo, no homologó plenamente los requisitos de origen, conservándose muchos de los que en forma específica rigen entre las partes en sus relaciones bilaterales y multilaterales existentes.

La libre circulación de capitales y la promoción de las inversiones se fundamenta en los capítulos de inversión de los tratados bilaterales de libre comercio que tienen las partes y en el caso de Perú y Colombia en el acuerdo autónomo de Promoción y Protección Recíproca de Inversiones. Obligaciones que se incorporaron en el capítulo 10 del Protocolo Adicional.

En relación con la promoción de la cooperación entre las autoridades migratorias y consulares para facilitar el movimiento de personas y el tránsito migratorio, evidenciamos solo dos avances, la eliminación de la exigencia de visas a nacionales de Colombia y de Perú por parte de México y el anuncio de Perú sobre la supresión de visas para personas de negocios de Chile, Colombia y México que realicen una actividad no remunerada.

En virtud de los acuerdos específicos suscritos entre los miembros de la Alianza hoy ya se comparten seis sedes diplomáticas (Ghana, Vietnam, Marruecos, Argelia, Azerbaiyán y la Misión Diplomática en la OCDE) y la séptima se estará implementando próximamente (Singapur).

El tratado constitutivo de la Alianza del Pacífico, configura una organización internacional restringida entre lo regional e intercontinental (pretende fortalecer los diferentes esquemas de integración en América Latina y mantener una proyección hacia la región de Asia Pacífico).

La Alianza, como organización internacional, tendría competencias especiales, referidas al sector económico (área de integración profunda para avanzar progresivamente hacia la libre circulación de bienes, servicios, capitales y personas), con características de coordinación e integración (construida, de manera participativa y consensuada).

No se evidencia cesión de competencias, por el contrario se enfatiza en la voluntad de constituirla como un espacio de concertación y convergencia que se haría efectivo de manera progresiva, participativa y consensuada. Así, estaríamos frente a una simple cooperación para coordinar y desarrollar intereses comunes entre los miembros.

El Tratado de Paranal solo menciona a quién le competen y cómo se adoptan las decisiones y que estas hacen parte de su ordenamiento jurídico. Sin embargo, no menciona 
el mecanismo de incorporación de estas decisiones y mucho menos hace referencia a la aplicación y efecto de las mismas.

El énfasis que se hace en el texto del tratado a la cooperación progresiva, participativa y consensuada, nos sitúa frente a una organización intergubernamental en la que sus decisiones requerirán consentimiento de los Estados para vincularlos.

De conformidad con el criterio de la personalidad jurídica objetiva, el contar con un órgano como el Consejo de Ministros con tareas específicas, la existencia de obligaciones de los miembros con respecto al desarrollo de los objetivos de la organización, las discusiones sobre aportes económicos para el Fondo de Cooperación y la eventual posesión de capacidad jurídica, privilegios e inmunidades que tendrían sus agentes en el territorio de los miembros, no nos dejan dudas acerca de la personalidad jurídica de la Alianza del Pacífico.

Queda por tanto resolver si la integración profunda pretendida, implica liberalización no solo de bienes y servicios, sino también de capital y personas. De ser así, conforme al marco teórico de la integración, necesariamente se fundamentaría en entes supranacionales decisorios que impongan patrones de conducta y administren el espacio económico que resulta fusionado (mercado común) para garantizar la plena liberalización de los bienes, servicios, capital y personas. De lo contrario, condenarían la eficacia de las cuatro libertades referidas a la revalidación política permanente por parte de los Estados miembros y someterían las decisiones adoptadas a mecanismos no automáticos de incorporación en las legislaciones internas.

Por ahora, la Alianza no es más que una zona de libre comercio, pese a que los gobiernos de los Estados que la componen insistan en que son más que un TLC.

\section{Referencias}

Agencia de la Promoción de la Inversión Privada en Perú. (s.f.). Disponible en: http:// www.proinversion.gob.pe/o/o/modulos/JER/PlantillaSectorHijo.aspx?ARE= o\&PFL=o\&JER=3860;

Alianza del Pacífico (2012). Alianza del Pacífico y sus objetivos. Disponible en: http:// alianzapacifico.net/en/home-eng/the-pacific-alliance-and-its-objectives/

Alianza del Pacífico (2012). Cooperación. Disponible en: http://alianzapacifico.net/ cooperacion/

Alianza del Pacífico (2012). Embajadas compartidas. Disponible en: http://alianzapacifico.net/embajadas-compartidas-entre-chile-colombia-mexico-y-peru-uno-delos-logros-de-la-alianza-del-pacifico/

Alianza del Pacífico (2012). Estructura y organigrama. Disponible en: http://alianzapacifico.net/que_es_la_alianza/estructura-y-organigrama/ 
Alianza del Pacífico (2012). Movimiento de personas. Disponible en: http://alianzapacifico.net/ movimiento-de-personas/

Asociación de Naciones del Sudeste Asiático, ASEAN (Association of Southeast Asian Nations) (s.f.). disponible en: www.asean.org/

Balassa, B. (1974). Trade Creation and Trade Diversion in the European Common Market: An Appraisal of the Evidence. Manchester School of Economic and Social Studies, 93-135. .

Balassa, B. (1989). Tariff Reductions and Trade in Manufactures among the Industrial Countries. En B. Balassa. Comparative Advantage, Trade Policy and Economic Development (pp. 131-39), Londres: Harvester Wheatsheaf.

Barbosa, F., Posada E., y Serrano E. (2011). La inserción de Colombia en Asía Pacífico 2020: Colombia en el nuevo océano. Bogotá: Universidad de Bogotá Jorge Tadeo Lozano.

Canovas, P. (2002). Planteamientos de la integración. Evolución de la integración en Latinoamérica. Madrid: Biblioteca Digital, Universidad Complutense.

Centro de Asia y el Pacífico para Estudios de Seguridad, APCSS (The Asia-Pacific Center for Security Studies) (s.f.). Disponible en: http://www.apcss.org/about-2/ ap-countries/

Congreso de la República de Colombia (2013). Ley 1628 de 2013, por medio de la cual se aprueba el “Acuerdo Marco de la Alianza del Pacífico”, entre la República de Colombia, la República de Chile, los Estados Unidos Mexicanos y la República del Perú, firmado en la ciudad de Antofagasta, Chile, el 6 de junio de 2012. Diario Oficial $n^{\circ} .48 .798$ del 22 de mayo de 2013.

Consejo Económico de la Cuenca del Pacífico, PBEC (Pacific Basin Economic Council). (s.f.). Disponible en: http://www.pbec.org/

Decisión 503 del 22 de junio de 2001, expedida por el Consejo Andino de Ministros de Relaciones Exteriores.

Díez de Velasco, M. (2008). Las organizaciones internacionales. Madrid: Tecnos.

Díez de Velasco, M. (2009). Instituciones de derecho internacional público. Madrid: Tecnos.

Dirección General de Relaciones Económicas Internacionales de Chile (s.f.). Disponible en: http://www.direcon.gob.cl/acuerdo/list;

Dromi R. et al. (1995). Derecho comunitario, sistemas de integración régimen del MERCOSUR, Buenos Aires: Ed. Ciudad Argentina. 
East Asia Forum (s.f..) Economics, Politics and Public Policy in East Asia and the Pacific. Disponible en: http://www.eastasiaforum.org/

Foro de Cooperación Económica de Asia-Pacífico, APEC (Asia Pacific Economic Cooperation) (s.f.) .Disponible en: http://www.apec.org/

Foro de Cooperación Económica del Pacífico, PECC (The Pacific Economic Cooperation Council) (s.f.) .Disponible en: https://www.pecc.org

González, P., Gutiérrez, M.Á. B. y Martín, R. D. (2010). ¿Qué es la integración económica? Universidad de Cantabria: http://ocw.unican.es/ciencias-sociales-y-juridicas/integracion-economica-europea/material-de-clase-1/modulo-3-integracion-europea/ tema-3.1-integracion-economica-europea.

Lawrence, R. Z. y Litan, R. (1990). The world trading system after the Uruguay round. Boston University International Law Journal, 8, 247-276 Disponible en: http:// heinonline.org/HOL/Page?handle=hein.journals/builj8\&div=19\&g_sent= $1 \&$ collection=journals $\# 253$

Ministerio de Comercio, Industria y Turismo de Colombia (s.f.). Disponible en: https:// www.mincomercio.gov.co/tlc/publicaciones.php?id=2534

Observatorio América Latina - Asia Pacífico (s.f.). Disponible en: http://www.observatorioasiapacifico.com/

Oyarzún Serrano, L. (2008). Sobre la naturaleza de la integración regional: teorías y debates. Revista de Ciencia Política, 95-113.

Pallares Bossa, J. (2004). Derecho internacional público. Bogotá: Leyer.

Pastor Ridruejo, J. A. (2010). Curso de derecho internacional público y organizaciones internacionales. Madrid: Tecnos.

Pereyra, D. M. (2007, agosto). Comercio e integración en África: el rol de la unión africana. Tesis no publicada presentada en la Maestría en Relaciones Económicas Internacionales; Buenos Aires, Universidad Nacional de La Matanza.

Pizzolo, C.(2002). Globalización e integración: ensayo de una teoría general. Buenos Aires: Ed, Ediar.

ProMéxico: Inversión y Comercio (s.f.) .Disponible en: http://www.promexico.gob. $\mathrm{mx} /$ es_us/promexico/Trade_agreements.Rodrik, D. (2012). La paradoja de la globalización. Barcelona: Ed. Antoni Bosch.

Protocolo Adicional al Acuerdo Marco de la Alianza del Pacífico (2012).Acuerdo Marco de la Alianza del Pacífico. Paranal, Antofagasta, República de Chile. Disponible en: http://alianzapacifico.net/documents/2014/PROTOCOLO_COMPLETO.pdf 
RCEP, Regional Comprehensive Economic Partnership (2013, julio 30). Issues and Way Forward. The Diplomat. Disponible en: http://thediplomat.com/2013/o7/ regional-comprehensive-economic-partnership-rcep-issues-and-way-forward/

Rodrik, D. (2012). La paradoja de la globalización. Barcelona: Ed. Antoni Bosch.

Schiff, M. y Winters, L. A. (1998). Regional Integration as Diplomacy. US: World Bank.

Schiff, M. y Winters, L. A. (2003). Integration Regional y Desarrollo. Bogotá: Banco Mundial y Alfaomega Colombiana.

Senarclens, P. de. (1993). La teoría de los regímenes y el estudio de las organizaciones internacionales. Revista Internacional de Ciencias Sociales, 529-539.

SICE, Sistema de Información del Comercio Exterior. (s.f.). Organización de Estados Americanos. Disponible en: http://www.sice.oas.org/

Tinbergen, J. (1954). International Economic Integration, Amsterdam: Elsevier.

Tratado de Estabilidad, Coordinación y Gobernanza en la Unión Económica y Monetaria. (2012, marzo 2). Disponible en: http://www.european-council.europa.eu/ media/639250/o2_-_tscg.es.12.pdf

Tremolada, E. (2013a). La Alianza del Pacífico: ¿̇una organización consecuente con sus objetivos? En Repensando la integración y las integraciones (pp. 233-258). Bogotá: Universidad Externado de Colombia,.

Tremolada, E. (2013b). ¿Los pilares que soportan la relación de la Unión Europea con América Latina contribuyen a su desarrollo? En Roy, J. (Comp). Después de Santiago: integración regional y relaciones Unión Europea América Latina (pp. 193-208). Miami - Florida: European Union Center, University of Miami.

Tremolada, Eric. (2013 c). “¿Los pilares que soportan la relación de la Unión Europea con América Latina contribuyen a su desarrollo?”, En Roy, Joaquín (Comp). Después de Santiago: integración regional y relaciones Unión Europea América Latina. Miami - Florida, EuropeanUnion Center, University of Miami, marzo, pp. 193-208.

Tremolada, E. (2014). La Alianza del Pacífico: ¿un instrumento idóneo para la inserción de Colombia en la región Asia-Pacífico? En Colombia en el Sistema Internacional: su proyección en Asia, (pp. 203-241) Bogotá: Universidad Externado de Colombia.

Tribunal de Justicia de las Comunidades Europeas, asunto Shull, (1982). sentencia del 5 de mayo de 1982.

Urueña, R. (2008). Derecho de las organizaciones internacionales. Bogotá: Uniandes-Temis. 
Viner, J. (1950). The Customs Union Issue. Nueva York: Fundación Carnegie para la Paz Internacional.

Vilar, F. (2013). La política comercial colombiana y sus esquemas de solución de controversias internacionales. En Tremolada, E. (Ed.). Repensando la integración y las integraciones. Bogotá: Universidad Externado de Colombia. 